\title{
Two Stage Optimization Models of the NCSRPE of Programs from the Perspective of Work
}

\author{
Daisong $\mathrm{HU}^{1,2,3}$, Jingchun FENG ${ }^{1,2, *}$, Wenjing ZHAO ${ }^{1,2}$, Yuwei ZHAI ${ }^{1,2}$, Song XUE ${ }^{1,2,4}$ \\ ${ }^{1}$ Business School, Hohai University, 210098, Nanjing, P.R.China \\ ${ }^{2}$ Institute of Project Management, 210098, Nanjing, P.R.China \\ ${ }^{3}$ International River Research Centre, 210098, Nanjing, P.R.China \\ ${ }^{4}$ Jiangsu Provincial Collaborative Innovation Center of World Water Valley and Water Ecological Civilization, 210098, Nanjing, \\ P.R.China
}

\begin{abstract}
Non-commercial resources provided by employers (NCRPE) are the imperative factor affecting the progress of engineering projects. However, the NCRPE with limited supply ability is rarely considered in the schedule optimization models in previous studies from the perspective of work. This paper analyzes the characteristics of the non-commercial single resource provided by employers (NCSRPE), the optimization principle, characteristics, and tasks. With the initial network, this paper researches the optimization model of the NCSRPE to minimize the supply capacity of the NCSRPE before the implementation and to reduce the actual demand of the NCSRPE to a level slightly below the supply capacity of the production system. NCSRPE optimization and re-optimization models are built based on this, and the Hybrid Particle Swarm Algorithm (HPSA) is used to solve the problem. The results show that the two models can effectively solve the optimization problem of program planning and adjustment under multiple independent stakeholders. Finally, resource balance before the implementation and the re-optimization of resource cutting during the implementation are carried out for artificial aggregate in Program X of the South-to-North Water Diversion Project (SNWDP) based on the HPSA. A reasonable and practical program planning and adjustment within different stakeholders can be obtained.
\end{abstract}

\section{Introduction}

\subsection{Research background}

There are two kinds of resources provided by employers: commercial resources provided by employers (CRPE) and non-commercial resources provided by employers (NCRPE). When providing non-commercial resources, employers need to build a corresponding production system, the capacity of which is mainly determined by the demand quantity of the NCRPE. Compared with the CRPE, the maximum demand for the NCRPE per unit time has a great impact on the cost of the program. It can be seen that it is common for employers to provide a supply of non-commercial resources through building production factories. In general, the proportion of NCRPE cost in engineering cost (contract price) varies greatly among different projects. This paper mainly studies projects with a significant proportion of NCRPE in engineering cost (contract price). It shows that artificial aggregate, a kind of non-commercial resources provided by employers (NCRPE), will have a significant impact on the investment of the project. At the same time, as the optimization of NCRPE often involves multiple stakeholders such as the employer and several contractors, the optimization problem becomes more complex.
Therefore, how to reduce the maximum demand for NCRPE by optimizing, so as to effectively control the cost of NCRPE is not only urgent, but also of great theoretical value and practical significance.

Through the analysis of the different consequences caused by the delay in each contracted project and each work, and the increase in the total cost of the delayed completion of the program, NCSRPE optimization, reoptimization models under multi contract environment, and the HPSA are used to solve the problem. The results show that the two models can effectively solve the optimization problem of program planning and adjustment under multiple independent stakeholders, thus, a more reasonable and practical program schedule and adjustment plan can be obtained. The results based on the HPSA can achieve the approximate optimal NCSRPE configuration of the whole program, thus, effectively improving the completion probability of the program.

\subsection{Formatting the title, authors and affiliations}

(1) Literature review on single project resource balance. Li et al., (2015) studied the resource leveling problem with uncertain activity duration, and proposed two heuristic algorithms for production scheduling strategies aiming at the expectation and minimization of the

* Corresponding author: huifeng07@hotmail.com 
weighted variation coefficient of resource utilization; Ponz-Tienda et al., (2017) improved the solution of multiresource RLP by an improved adaptive harmony search (IAHS) algorithm and applied it to 71 building projects, and it was proved that the algorithm was faster and more effective than other meta-heuristic algorithms by comparison; Selvam et al., (2019) developed a method to solve the resource leveling problem with precedence constrained scheduling using Genetic Algorithm and proved that this method was superior to existing business management software. The above researches on resource leveling and resource allocation in solving project uncertainties, minimizing project cost and duration, and minimizing resource fluctuation have achieved remarkable results, mainly involving the establishment of traditional models and methods and the improvement of intelligent algorithms. However, the above researches only involve single project.

(2) Review of existing research results. The existing researches on resource leveling mainly focus on the modeling and solving of uncertain factors, and the innovation of models and methods for solving resource leveling with minimum cost, minimum duration or multiobjective optimization as well as the presentation and improvement of various intelligent algorithms for resource leveling.

This paper analyses the optimization principle of the NCRPE of the program in different cases, and constructs the two-stage optimization model of the NCRPE. This paper applies the two-stage optimization model of the NCRPE to the actual case, and provides new solutions and methods for the optimization of the NCRPE. The optimization model of NCSRPE is also studied in this paper.

\section{Analysis on the Characteristics and Optimization Principle of the NCSRPE for a Program Based on Work}

\subsection{Definitions of Questions}

(1) The limitation of the NCSRPE often leads to delays in the project schedule. However, during the low period of the use of the NCSRPE, the utilization rate of the NCSRPE will be low, resulting in unnecessary waste. Two problems need to be solved: firstly, in the preparation of program schedule, resource optimization is required to realize the balance of the NCSRPE under the condition of a fixed schedule; the second is to ensure that the existing supply capacity can meet the needs of the NCSRPE during the implementation of the program.

(2) The simultaneous implementation of multiple contracted projects and multiple work in the program may result in a shortage of the NCSRPE, further resulting in the delay of the program. When making optimization of the NCSRPE, it is necessary to consider the schedule of the contracted projects and their work, as well as the loss caused by the delay of the contracted projects and their work.
(3) The research results of the existing resource balance mainly focus on the optimization of resources of the single contracted project, especially the improvement of various intelligent algorithms, etc. In the research results of program schedule optimization, the contracted projects are the object of optimization instead of each work, which is not consistent with the actual situation. This paper constructs the optimization objective function by analyzing and calculating the delay penalty caused by various work. Therefore, this paper studies the optimization problem of the NCSRPE for the program based on work, and constructs the optimization model.

\subsection{Analysis of the characteristics of the NCSRPE of the program based on work}

(1) Demand characteristics of the NCSRPE of the program. Firstly, compared with the single project, the total of the NCSRPE for a program is large and the distribution could be more imbalanced. Secondly, the NCSRPE is needed by multi-projects at the same time. It is necessary to optimize the NCSRPE for the program to maximize the balance of the NCSRPE. Lastly, the chain effect of the program is more obvious. Multiple contracted projects and multiple work sharing the same resource may have a chain effect, and this chain effect of the program is more obvious than that within a single project.

(2) Supply characteristics of production system of the NCSRPE. Firstly, the production is uneven. The supply capacity of the production system of the NCSRPE needs to be planned based on the month with the peak demand. Secondly, the supply capacity of the NCSRPE is adjusted to meet the demand amount. On the one hand, it is essential to determine the type and quantity of system equipment configuration according to the demand amount of the NCSRPE for the schedule; on the other hand, it needs to supply the finished product for the NCSRPE in a timely manner with the quality and quantity guaranteed based on actual needs. Therefore, there will be a contradiction between the quality and quantity in the supply and demand of the NCSRPE.

\subsection{Optimization principle of the NCSRPE for the program based on work}

The NCSRPE refers to the required amount of resources that the employer supplies by building specialized production systems based on the program. The cost depends on the supply capacity of the NCSRPE. For the NCSRPE, since a separate production system needs to be built, the imbalance of the NCSRPE greatly increases the employers' expenses. For the optimization of the NCSRPE of the program, it should be divided into two stages: before and during the implementation of the program.

(1) Before the implementation, it is necessary to optimize the program schedule without considering resource constraints. Since the employer does not sign contracts with the contractors at this stage, there is no penalty in the optimization of resources as long as the start 
time of work on critical path in the program is not changed. The supply capacity of the NCSRPE needs to meet the needs at the peak of the NCSRPE of the program. Therefore, it is necessary to reduce the peak demand intensity of the NCSRPE as much as possible so as to reduce unit cost of the NCSRPE. At this point, the purpose of optimization is to reduce the increased costs due to the imbalance of the NCSRPE.

(2) During the implementation, because of multiple contractors of the program, schedule changes of contracted projects may affect the schedule of other contracted projects as well as the program, will cause fluctuations of the supply capacity of the NCSRPE, and is likely to break the initial state of the NCSRPE optimization, generating additional costs. In this case, with the optimization of the initial schedule plan, it is necessary to weigh the interests of each contractor and take into consideration comprehensively the differences of the delay costs of different contracted projects, so as to realize the optimal allocation of the NCSRPE.

\section{Building of Optimization and Re- optimization Models of the NCSRPE for the Program Based on Work}

Firstly, the initial schedule of the program with the lowest supply capacity of the NCSRPE as the optimization objective is optimized under the premise of fixed program schedule before the implementation; secondly, in the implementation process, when the delay of the contracted projects and their work causes the maximum supply capacity of the NCSRPE to exceed the existing supply capacity of the NCSRPE, on the premise that the schedule of the program is fixed, the demand amount of the NCSRPE shall meet the supply capacity.

\subsection{Assumptions}

The basic idea to solve the problem is to optimize the NCSRPE by adjusting the earliest start time and actual start time of each contracted project and its work. The assumptions in this paper are as follows:

(1) The object that needs optimization in this paper is work;

(2) Bidding for all contracted projects of the program shall be conducted simultaneously.

(3) In the process of optimization and reoptimization the NCSRPE, the critical path remains unchanged. At the same time, the logical relationship and schedule between the contracted projects and their work remain unchanged.

(4) Once work begins, no interruption is allowed.

(5) The NCSRPE demand amount of each contracted project and its work shall be known and unchanged, and the schedule shall not be changed by temporarily increasing or decreasing resources.

\subsection{Meanings of model symbols}

Meanings of model symbols in this paper are shown in Table 1.

Table 1. Meanings of model symbols

\begin{tabular}{|c|c|}
\hline Symbol & Meaning \\
\hline RV & resource variance of the NCSRPE R \\
\hline $\mathrm{R}(\mathrm{t})$ & consumption of Resource $\mathrm{R}$ for $\mathrm{m}$ contracted projects in the th unit time \\
\hline $\mathrm{T}$ & total project schedule of the program \\
\hline $\mathrm{t}$ & the th unit time, $\mathrm{t}=1,2 \ldots \mathrm{T}$ \\
\hline $\bar{R}$ & the mean of Resource R \\
\hline Tij & the jth work in the ith project \\
\hline Rt(Tij) & the consumption of Work Tij of the resource in the tth unit time \\
\hline TA(i) & the work set for the ith project \\
\hline ES(Tij) & the earliest start time of work \\
\hline LS(Tij) & the latest start time of work \\
\hline AST(Tij) & the actual start time of work \\
\hline AFT(Tij) & the actual completion time of work \\
\hline $\mathrm{D}(\mathrm{Tij})$ & schedule of work \\
\hline S(Tij) & slack time of work \\
\hline $\operatorname{vag}($ Tij) & work set of predecessor work \\
\hline $\mathrm{C}$ & payment by the employer \\
\hline$f_{i}$ & the amount of the ith contract, $i=1,2 \ldots \mathrm{m}$ \\
\hline$\alpha_{i j}$ & $\begin{array}{l}\text { the rate of claim of the jth work of the ith contracted project for the schedule prolonging due to } \\
\text { delay of previous work, } \mathrm{j}=1,2 \ldots, \mathrm{n}\end{array}$ \\
\hline$\beta_{i j}$ & $\begin{array}{l}\text { the rate of claim of the jth work of the ith contracted project for the schedule prolonging due to } \\
\text { the resource optimization }\end{array}$ \\
\hline$\varepsilon_{i j}$ & $\begin{array}{l}\text { the rush rate claimed for the jth work of the ith contracted project due to the resource } \\
\text { optimization }\end{array}$ \\
\hline$\delta_{i j}$ & $\begin{array}{l}\text { the rate of claim of the jth work of the ith contracted project for the schedule delay due to the } \\
\text { resource optimization }\end{array}$ \\
\hline$\theta_{i j}$ & $\begin{array}{l}\text { the schedule prolonging of the jth work of the ith contracted project due to delay of previous } \\
\text { work }\end{array}$ \\
\hline$\gamma_{i j}$ & $\begin{array}{c}\text { the schedule prolonging of the jth work of the ith contracted project due to resource } \\
\text { optimization }\end{array}$ \\
\hline
\end{tabular}




\begin{tabular}{|c|c|}
\hline$\mu_{i j}$ & rush time of the jth work of the ith contracted project due to resource optimization \\
\hline$\rho_{i j}$ & delay time of the jth work of the ith contracted project due to resource optimization \\
\hline$R(t)^{\prime}$ & $\begin{array}{c}\text { consumption of Resource } \mathrm{R} \text { of } \mathrm{m} \text { contracted projects in the th unit time due to a schedule } \\
\text { change }\end{array}$ \\
\hline$R\left(T_{i j}\right)^{\prime}$ & consumption of the resource of Work Tij in the th unit time due to a schedule change \\
\hline$A S T\left(T_{i j}\right)^{\prime}$ & the actual start time of the jth work of the ith contracted project after the schedule adjustment \\
\hline $\operatorname{AFT}\left(T_{i j}\right)^{\prime}$ & $\begin{array}{c}\text { the actual completion time of the jth work of the ith contracted project after the schedule } \\
\text { adjustment }\end{array}$ \\
\hline RS & the maximum supply capacity of the non-commercial resources provided by employers \\
\hline $\mathrm{Cij}$ & the rates of schedule changes \\
\hline
\end{tabular}

\subsection{Optimization model of the NCSRPE for the program before implementation based on work}

According to the conflict of the NCSRPE, by optimizing the contracted projects of the initial schedule, the resource balance configuration of the program can be conducted, namely, through reasonably arranging the earliest start time of each work on the non-critical path of the contracted projects of the program, making the variance of the NCSRPE minimum, and achieving the maximum balance degree for the NCSRPE, in order to reduce the peak value of the demand for the NCSRPE.

\subsubsection{Optimization model of the NCSRPE for the program before implementation}

According to the logical and resource constraints, the cost of the program can be reduced by adjusting the work in the contracted projects of the program. In other words, the start time of each work in the program can be reasonably arranged to realize the balance allocation of the NCSRPE before the implementation of the program. Suppose there are $\mathrm{m}$ contracted projects in the program, each of which contains multiple work, then, the mathematical model for the balance problem of the NCSRPE for the program is as follows:

(1) objective function:

$$
\min R V=\frac{1}{T} \sum_{t=1}^{T}(R(t)-\bar{R})^{2}, \bar{R}=\frac{1}{T} \sum_{t=1}^{T} R(t)(1)
$$

(2) constraint conditions:

$$
\begin{aligned}
& \operatorname{ES}\left(T_{i j}\right) \leq \operatorname{AST}\left(T_{i j}\right) \leq \operatorname{LS}\left(T_{i j}\right)(2) \\
& \max \left\{\operatorname{AFT}\left(\operatorname{vag}\left(T_{i j}\right)\right)\right\} \leq \operatorname{AST}\left(T_{i j}\right)(3) \\
& R(t)=\sum_{i=1}^{n} \sum_{j \in\{T A(i)\}} R_{t}\left(T_{i j}\right)(4) \\
& R\left(T_{i j}\right)=\left\{\begin{array}{c}
R\left(T_{i j}\right), \quad A S T\left(T_{i j}\right)<t \leq A F T\left(T_{i j}\right) \\
0, t \leq A S T\left(T_{i j}\right) \text { or } t>A F T\left(T_{i j}\right)
\end{array}\right. \\
& S\left(T_{i j}\right)=L S\left(T_{i j}\right)-E S\left(T_{i j}\right)(6) \\
& T=\max \left\{L S\left(T_{i j}\right)+D\left(T_{i j}\right)\right\}-\min \left\{E S\left(T_{i j}\right)\right\}(7)
\end{aligned}
$$

Where, Formula (1) is the objective function, which represents the minimum variance of the NCSRPE in the program; Formulas (2) and (3) are constraints on the commencement time. Formula (2) indicates that the actual commencement time should be limited to the schedule between the earliest commencement time and the latest commencement time. Formula (3) indicates that the actual commencement time shall be limited by the actual completion time of the predecessor work. Formula (4) represents the consumption of the resource by $n$ projects on the th day; Formula (5) is the consumption of the resource per unit time by Tij of the th day; Equation (6) is the relaxation time, which represents the span between the latest start time and the earliest start time; Formula (7) refers to the total schedule of the program, the span between the start time of the earliest project and the completion time of the latest project.

According to the optimization model of the NCSRPE before program implementation (see Formulas (1)-(7)), the maximum supply capacity (RS) of the NCSRPE can be obtained. In this case, the variance of the supply capacity of the NCSRPE is the smallest.

\subsection{Re-optimization model of the NCSRPE for the program during implementation based on work}

\subsubsection{Re-optimization principle}

In the implementation of the program, due to the employer, contractor, force majeure, etc., delays may happen in the schedule of work, contracted project, and program, which will likely break the optimal state before carrying out the program, thus, resulting in the fact that the actual demand of the NCSRPE is more than the supply capacity of the NCSRPE. In this case, generally, it is difficult to meet the actual demand by expanding the supply capacity of the NCSRPE. Therefore, it is necessary to reoptimize the schedule of the program obtained by optimization before the implementation of the program and adjust the schedule of the successive contracted projects and its work of the program, namely, reducing the demand peak of the NCSRPE to make the actual demand for the NCSRPE within the maximum supply capacity. At the same time, the adjustment of the programs chedule may affect the arrangement of the equipment, personnel, and materials of the contractor for the successive contracted projects, resulting in the schedule and/or economic losses to the contractor. In this case, the employer shall bear the losses caused to the relevant contractors. Therefore, from the perspective of the employer, with the lowest cost paid by the employer as the reoptimization objective, the maximum supply capacity of the NCSRPE can be optimized. 


\subsubsection{Reoptimization model of the NCSRPE for the program during implementation}

When a schedule delay occurs in work of the program, it could lead to the fact that the demand amount of the NCSRPE exceeds the maximum supply capacity (RS); then, it is necessary to reoptimize the NCSRPE. That is, the maximum actual demand amount of the NCSRPE is less than or equal to the maximum supply capacity (RS) by adjusting the earliest start time of the subsequent contracted projects and their work of the work delayed. If necessary, the NCSRPE of the program can be reoptimized for the third, the fourth, ..., the nth time. The purpose is to make the supply capacity of the NCSRPE meet the maximum demand amount of the NCSRPE by reducing or extending the duration of the contracted projects and their work with the minimum cost paid by the employer as the reoptimization objective. The mathematical model for reoptimizing the NCSRPE is as follows:

(1) objective function:

$\min C=\sum_{i=1}^{m} \sum_{j=1}^{n}\left(\alpha_{i j} \theta_{i j}+\beta_{i j} \gamma_{i j}+\varepsilon_{i j} \mu_{i j}+\delta_{i j} \rho_{i j}\right) \times f_{i}$

(2) constraint conditions:

$$
\begin{aligned}
& \operatorname{ES}\left(T_{i j}\right) \leq \operatorname{AST}\left(T_{i j}\right)^{\prime} \leq L S\left(T_{i j}\right) \\
& \max \left\{\operatorname{AFT}\left(\operatorname{vag}\left(T_{i j}\right)\right)^{\prime}\right\} \leq \operatorname{AST}\left(T_{i j}\right)^{\prime} \\
& \max R(t)^{\prime} \leq R_{S}, \mathrm{t}=1,2, \cdots, \mathrm{T} \\
& \theta_{i j}+\gamma_{i j} \leq L F\left(T_{i j}\right)-E F\left(T_{i j}\right) \\
& R(t)^{\prime}=\sum_{i=1}^{n} \sum_{j \in\{T A(i)\}} R_{t}\left(T_{i j}\right)^{\prime} \\
& R\left(T_{i j}\right)^{\prime}=\left\{\begin{array}{c}
R\left(T_{i j}\right)^{\prime}, \quad A S T\left(T_{i j}\right)^{\prime}<t \leq A F T\left(T_{i j}\right)^{\prime} \\
0, t \leq A S T\left(T_{i j}\right)^{\prime} \text { or } t>A F T\left(T_{i j}\right)^{\prime}
\end{array}\right.
\end{aligned}
$$

Where, Formula(8) is the objective function, representing the claim costs against the employer due to the adjustment to the schedule of the contracted projects and work of the program. For particular Work Wij (the jth work of the ith project), here the costs include two parts: one is the claim cost that the employer pays for the schedule delay of Work Wij due to the delays of the predecessor work; the other is the claim cost that the employer pays for Work $\mathrm{Wij}$ due to the resource reoptimization for the second time and third time, which includes the cost for the schedule prolonged, schedule rushed, and schedule delayed. Formulas (9) and (10) are the constraints of the start time, and their specific meanings are the same as that by Formulas (2) and (3); Formula (11) is the constraint of resource consumption per unit time, i.e., the total resource consumption per unit time should meet the constraint of the maximum supply capacity; Formula (12) refers to the time constraint of the schedule adjustment, i.e., the total delay time of each contracted project and their work shall not exceed the total float; Formula (13) represents the consumption of the resource by $\mathrm{n}$ projects on the th working day after the earliest start time of each contracted project and their work is adjusted; Formula (14) represents the consumption of the resource per unit time by Work Tijon the th working day after the earliest start time of each contracted project and their work is adjusted.

\subsection{Reoptimization steps of the NCSRPE}

The reoptimization of the NCSRPE in the program can be divided into five stages. The specific steps are as follows:

(1) Before the implementation of the project (before bidding), the NCSRPE is optimized for the first time, that is, the entire resources of the program shall be balanced to reach the maximum supply capacity(RS) of the resources that the employer can supply per unit time.

(2) In the process of program implementation, when the schedule is delayed, the time t_c $\left(\mathrm{t} \_\mathrm{c}<\mathrm{T}\right)$ when the resource demand amount exceeds its supply amount available is determined.

(3) Determine the work to be reoptimized. For the work whose start time is less than time t_c, it is not reoptimized. For the work whose start time is equal to time t_c, reoptimization object of the work with free float or total float and occupying the NCSRPE for the second time is chosen. For the work whose start time is greater than time t_c, adjust the start time on the premise of satisfying the logical relationship and resource consumption. When the contracted projects are optimized but still cannot meet the requirements, the resources need to be optimized for the third time, the fourth time, ..., the nth time, until the requirements are met.

(4) Calculate the total cost $\mathrm{C}$ of schedule change. The delay time is expressed by

$$
\Delta t_{i j}\left(\Delta t_{i j}=\theta_{i j}+\gamma_{i j}, \quad 0<\Delta t_{i j} \leq L F\left(T_{i j}\right)-E F\left(T_{i j}\right)\right)(15)
$$

(5) Analyze, adjust, and optimize continuously, and finally obtain the progress plan after the optimization of the program resources.

\section{Case Study}

\subsection{Case background}

This case is about Program $\mathrm{X}$ of the SNWDP, which is composed of three contracted projects with a total schedule of 60 months, and each contracted project is composed of eight work. See Figure 1and Table 2 for the initial network and basic information of the schedule of Program X. In Figure 1, above the work arrow line is the work number and the amount of the NCSRPE used, while below the work arrow line is the duration of each work. 




Figure 1 Initial schedule and basic information of each work of Program X

Table 2 Basic information of Program X

\begin{tabular}{|c|c|c|c|c|c|c|}
\hline$\underset{r}{\text { Numbe }}$ & $\begin{array}{l}\text { Name of } \\
\text { Contracted } \\
\text { Project }\end{array}$ & $\begin{array}{c}\text { Contract } \\
\text { Amount } \\
\text { (Ten } \\
\text { Thousand } \\
\text { CNY) } \\
\end{array}$ & $\begin{array}{l}\text { Work } \\
\text { Name }\end{array}$ & $\begin{array}{l}\text { Duration(m } \\
\text { onth) }\end{array}$ & $\begin{array}{c}\text { Concrete } \\
\text { Demand } \\
\text { Amount Per } \\
\text { Month }\left(\mathbf{k m}^{3} / \mathbf{m o}\right. \\
\text { nth) } \\
\end{array}$ & $\begin{array}{c}\text { Concrete } \\
\text { Demand Amount } \\
\text { Under Initial } \\
\text { Schedule }\end{array}$ \\
\hline 1 & \multirow{8}{*}{$\begin{array}{c}\text { Contracted } \\
\text { Project } \\
\text { X1(Contractor } \\
\text { X1) }\end{array}$} & \multirow{8}{*}{7249.00} & A1 & 2 & 3 & \multirow{18}{*}{$\begin{array}{l}\text { (1)Maximum } \\
\text { concrete demand } \\
\text { amount per } \\
\text { month: } 19.00 \\
\mathrm{~km}^{3} / \text { month; } \\
(2) \text { Variance of } \\
\text { concrete demand } \\
\text { amount per } \\
\text { month: } \\
8.395 \mathrm{~km}^{3} / \text { month. }\end{array}$} \\
\hline 2 & & & B1 & 5 & 4 & \\
\hline 3 & & & $\mathrm{C} 1$ & 6 & 4 & \\
\hline 4 & & & D1 & 5 & 5 & \\
\hline 5 & & & E1 & 5 & 3 & \\
\hline 6 & & & $\mathrm{~F} 1$ & 6 & 9 & \\
\hline 7 & & & G1 & 4 & 2 & \\
\hline 8 & & & H1 & 4 & 0 & \\
\hline 9 & \multirow{8}{*}{$\begin{array}{c}\text { Contracted } \\
\text { Project } \\
\text { X2(Contractor } \\
\text { X2) }\end{array}$} & \multirow{8}{*}{5937.00} & A2 & 3 & 5 & \\
\hline 10 & & & B2 & 15 & 8 & \\
\hline 11 & & & $\mathrm{C} 2$ & 4 & 0 & \\
\hline 12 & & & $\mathrm{D} 2$ & 5 & 5 & \\
\hline 13 & & & E2 & 6 & 1 & \\
\hline 14 & & & $\mathrm{~F} 2$ & 5 & 9 & \\
\hline 15 & & & G2 & 5 & 2 & \\
\hline 16 & & & $\mathrm{H} 2$ & 4 & 5 & \\
\hline 17 & \multirow{2}{*}{$\begin{array}{l}\text { Contracted } \\
\text { Project }\end{array}$} & \multirow{2}{*}{9800.00} & A3 & 2 & 4 & \\
\hline 18 & & & B3 & 12 & 8 & \\
\hline
\end{tabular}




\begin{tabular}{|c|c|c|c|c|}
\hline 19 & \multirow{6}{*}{$\begin{array}{c}\text { 3(Contractor } \\
\text { X3) }\end{array}$} & C3 & 5 & 0 \\
\hline 20 & & D3 & 5 & 2 \\
\hline 21 & & E3 & 6 & 1 \\
\hline 22 & & F3 & 9 & 9 \\
\hline 23 & & G3 & 5 & 5 \\
\hline 24 & & H3 & 3 & 2 \\
\hline
\end{tabular}

\subsection{Analysis on concrete optimization of Program X}

Program $\mathrm{X}$ shares the artificial aggregate production system that concrete needs, and the employer needs to arrange and manage the three contracted projects and each work of Program X. The NCSRPE of Program X is artificial aggregate, which is shared by the three contracted projects and various work of Program X. For this purpose, the employer needs to solve two problems: Firstly, before starting Program X, the employer needs to divide the artificial aggregate system into a section and make a separate tender. In this case, to reduce the scale of the production system of the artificial aggregate to a minimum, the employer needs to optimize the schedule of Program X, to make the peak demand for artificial aggregate fall to the lowest; secondly, in the implementation of Program X, once the work schedule is delayed and the actual demand amount for artificial aggregate is greater than the maximum supply capacity of the artificial aggregate production system, the employer needs to reduce the peak demand amount for artificial aggregate to the maximum supply capacity that can be provided by the artificial aggregate production system.

\subsection{Concrete Balance Configuration before Implementation of Program X}

This paper uses software, MATLAB R2014 to optimize the concrete demand amount of Program X, that is, to solve the resource balance allocation model before the implementation of Program X. The hybrid algorithm of the simulated annealing particle swarm has advantages such as concise concept, easy implementation, high precision, and fast convergence, has the ability of a sudden jump in the process of searching the optimal solution, and can effectively avoid searching into local optimal solution, to enhance the global search ability of the particle, so, finally, it is adopted to solve the model. After calculation, based on the hybrid algorithm of the simulated annealing particle swarm, the variance optimization results of the concrete balance model of Program $\mathrm{X}$ are obtained, as shown in Figure 2.



Figure 2 Balance variance optimization results of concrete before implementation

Figure 2 shows the balance result of concrete consumption of Program X before its implementation. It can be seen that after the schedule of the contracted projects and their work on the non-critical path has been iterated for 10 times, the variance becomes smaller and gradually converges at 6.49 . At this time, when the variance is minimal, the schedule adjustment scheme of each contracted project and their work on the non-critical path of Program $\mathrm{X}$ is shown in Table 3.

Table 3 Schedule adjustment plan of concrete balance before the implementation of Program X

\begin{tabular}{|l|l|l|l|l|l|l|}
\hline work & B1 & D1 & E1 & A2 & C2 & D2 \\
\hline $\begin{array}{l}\text { Adjustment } \\
\text { time }\end{array}$ & 0 & 1 & 1 & 1 & 2 & 5 \\
\hline work & H2 & A3 & C3 & D3 & E3 & H3 \\
\hline $\begin{array}{l}\text { Adjustment } \\
\text { time }\end{array}$ & 0 & 3 & 10 & 0 & 0 & 0 \\
\hline
\end{tabular}

Also, when the variance is minimal, the final concrete distribution per unit time is shown in Figure 3. 


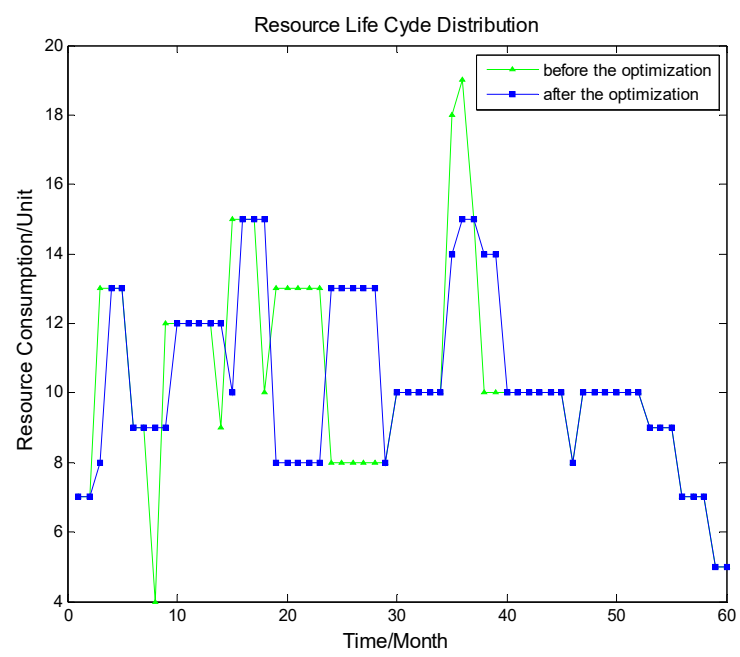

Figure 3 Comparison of concrete supply capacity before and after the implementation

Figure 3 shows that before the optimization, the maximum demand amount of concrete per unit time was $19 \mathrm{~km} 3 /$ month and the maximum supply capacity of concrete after the optimization is $15 \mathrm{~km} 3 /$ month, which has been reduced by $21.05 \%$ compared with that before the optimization. According to the variance calculation formula which is shown in formula (1), the variance of concrete demand amount per unit time was 8.395 $\mathrm{km} 3 /$ month before the optimization, while it is 6.497 $\mathrm{km} 3 /$ month after the optimization, , reduced by $22.60 \%$ compared with that before the optimization.

\subsection{Reoptimization of the NCSRPE during the implementation of Program X}

After determining the maximum concrete supply capacity, the employer begins and implements bidding for the artificial aggregate system and various contracted projects. During the implementation, the work may be delayed due to force majeure, the employer's reasons, the contractor's reasons, changes, etc. which may affect the start time and schedule of subsequent contracted projects and their work, and make the resource demand amount of subsequent contracted projects and their work unit time exceed its maximum supply capacity. At this time, it is necessary to reoptimize the resource for the second time and third time.

Work D2 was delayed for seven months due to some reasons, making Work D2, which could have ended in the 28 th month, completed in the 35 th month. At this time, due to the delay in the schedule of Work D2, resource consumption in the 35th month increases to 19 $\mathrm{km} 3 /$ month, which exceeds the maximum concrete supply capacity, i.e., $15 \mathrm{~km} 3 /$ month. Now it is necessary to conduct the secondary reoptimization for the concrete resources. It is assumed that in the secondary reoptimization of the resources when the employer delays or advances the schedule of each project or its work, the corresponding contractor can claim against the employer each month for $2 \%$ of the contractprice, and when the employer rushes or prolongs each project or its work, the corresponding contractor can claim against the employer each month for $5 \%$ of the contract price.

Since the delay of the work on the critical path will affect the schedule of Program X, the work on the noncritical path will be adjusted in priority. According to the amount of claim, the work on the non-critical path with free float has the priority in advancing, delaying, compressing, and prolonging with free float, followed by the compression and adjustment of the schedule of the work without free float.

(1) Resource reoptimization is carried out for the project or its work consuming concrete provided by the employer at time t28, namely, Work E2, H2, and B3. Considering the free float and total time difference of the work, Work H2 is taken as the reoptimization object and its schedule is delayed for one month, so that the concrete consumption at time 28 can be reduced to $14 \mathrm{~km} 3 / \mathrm{month}$, which is lower than the monthly maximum supply capacity. In this case, the employer should compensate Contractor2 119,500 CNY.

(2) The delay of Work $\mathrm{H} 2$ makes the resource consumption at time $\mathrm{t} 38$ more than the monthly maximum supply capacity, $19 \mathrm{~km} 3 /$ month. Reoptimization is conducted for the work involved at time t38. Considering the free float and total float of the work, A3 is taken as the reoptimization object, and its schedule is delayed for one month, so that the concrete demand amount at time $\mathrm{t} 38 \mathrm{can}$ be reduced to $14 \mathrm{~m} 3 /$ month, lower than the monthly maximum supply capacity. At this point, the employer should compensate Contractor X3 196,000 CNY. After the second reoptimization, the total amount that the employer should compensate the contractor is 315,500 CNY. Finally, through the second reoptimization of the resources, the problem that the resources exceed the monthly maximum supply capacity caused by the delay of the schedule can be alleviated and solved.

\subsection{Results analysis}

(1) The conflict of the NCSRPE can be effectively dealt with by sharing. The final adjustment results show that the supply of the NCSRPE during this period can meet the actual demand amount for the resources of Program X, avoiding the schedule delay of Program $\mathrm{X}$ caused by resource conflicts. Before the first time balance optimization of the resources, the maximum demand amount for the NCSRPE was $19 \mathrm{~km} 3 /$ month, which has been decreased by $4 \mathrm{~km} 3 /$ month, and by $21.05 \%$ after the balance resource optimization, namely, the employer's costs for making the production system has been decreased by $21.05 \%$; the variance of the NCSRPE before the optimization was 8.40 , and is 6.50after the optimization, which is 1.9 lower than that before the optimization, and has been decreased by $22.62 \%$. The balance of the NCSRPE is also significantly improved, and the optimization effect is obvious. Before the second reoptimization of the resources, the resource consumption at timet 35 breaks through the monthly maximum supply capacity due to the delay in the schedule of D2, but after the second reoptimization, the resource consumption peak 
is reduced to below the monthly maximum supply capacity.

(2) When the resource balance is optimized before and during the implementation of Program $\mathrm{X}$, the total schedule remains unchanged. The start time of D1, E1, A2, $\mathrm{C} 2, \mathrm{D} 2, \mathrm{H} 2, \mathrm{~A} 3$, and $\mathrm{C} 3$ is changed, $\mathrm{D} 1, \mathrm{E} 1, \mathrm{~A} 2$, and $\mathrm{H} 2$ are all delayed for 1 month, C2 2 months, A34 months, and C3 10 months, but the delay time of each of the work is not greater than the free float, so the delay only affects their start time, but has no effect on the start time of the predecessor work or projects. As a result, the employer needs to compensate Contractors $\mathrm{X} 1$ and Contractor $\mathrm{X} 2119,500 \mathrm{CNY}$ and 196,000 CNY respectively, totally $315,500 \mathrm{CNY}$; the critical path has not been changed, and the entire adjustment process has not changed the schedule of Program X.

(3) The optimization cost of the NCSRPE for Program $\mathrm{X}$ based on work is lower than that based on the contracted projects. If the contracted project is taken as the optimization object, then what can be done is to postpone Contracted Project X3 for three months. If so, the employer needs to compensate 588,000 CNY, which is $86.37 \%$ higher than that of taking the work as the optimization object. In addition, as the contracted project is on the critical path of Program X, it will make Program $\mathrm{X}$ delayed for three months, which will make the employer suffer loss from this part of Program X.

\section{Conclusions}

In the process of program implementation, the resource allocation model should be established suitable for the whole program goal from the perspective of not only the contractor of the single projects, but also the overall time and space. Based on the strategic goal and the characteristics of resource utilization, the resource quantity needed is calculated from the viewpoints of time and space of the program. By optimizing the schedule, the supply capacity of resources before implementation is determined, the peak value of resources during implementation is reduced, and the overall benefit is maximized. The mathematical model established during the research provides a way of thinking for program scheduling before program implementation. Through the case study, conclusions are drawn as the following:

(1) Compared with the optimization of the NCSRPE of a single project, the optimization object of the NCSRPE of a program is complex and there are many optimization factors to be considered. The NCSRPE of a program needs to consider many interest subjects and the resource conflicts between different work of the same interest subject, so it is necessary to adjust the schedule of different contracted projects of the program and the different work of the same contracted project. It can be seen that the optimization of the NCSRPE in the program is more complex.

(2) Work is used as the research object in this paper; the optimization curve of the NCSRPE of the program based on the work is more in line with the actual situation. After calculation, it can be found that the optimization cost of the NCSRPE of the program based on work is lower than that based on the contracted project. If the contracted project of the program is taken as the optimization object, Contracted Project X3 can only be postponed for three months. In this case, the employer should compensate $588,000 \mathrm{CNY}$, which is $86.37 \%$ more than that of taking the work as the optimization object. At the same time, because $\mathrm{X} 3$ is on the critical path of the program, the delay of X3 for three months will cause the program to be delayed for three months, at this time, the employer will also bear the loss resulting from the program.

(3) During the implementation of the program, once the actual demand amount for the NCSRPE is greater than the supply capacity due to the delay of schedule of the contracted project and its work, the peak of the demand amount of the NCSRPE will be reduced to the maximum supply capacity by optimizing the program schedule, so as to effectively solve the conflict of the NCSRPE.

For program managers, it is necessary to consider the resource adjustment plan from the perspective of the whole program by comprehensively analyzing the difference in the costs of the delay caused by work adjustment of each project. In actual programs, the construction plans are often affected by a variety of resources. Further study is required on the issue of designing a reasonable coordination mechanism to deal with the multi-resource conflict of the program.

\section{Acknowledgement}

This research was supported by the Major Project of National Social Science Found of China: Research on the coordinated development and security strategy of waterenergy-food in China under the green development(19ZDA084). The authors are grateful to the Office of the South-to-North Water Diversion Project Construction Committee under the State Council.

\section{References}

1. A. Viana, J.P.de Sousa, Using metaheuristics in multi objective resource constrained project scheduling, European Journal of Operational Research 120 (2) (2000)

2. Cheng, M. Y., Prayogo, D., \&Tran, D. H.. Optimizing Multiple-Resources Leveling in Multiple Projects Using Discrete Symbiotic Organisms Search. Journal of Computing in Civil Engineering, (2015)

3. Doulabi, S. H. H., Seifi, A., \& Shariat, S. Y.. Efficient hybrid genetic algorithm for resource leveling via activity splitting. Journal of Construction Engineering and Management, 137(2), (2010)

4. Duan, S., \&Zhang, J.. Multi-Project Resource Leveling Allocation Research Based on Improved Genetic Algorithm. Journal of Industrial Technological Economics, 36(10), (2017) (in Chinese)

5. El-Abbasy, M. S., Elazouni, A., \&Zayed, T.. Generic Scheduling Optimization Model for Multiple 
Construction Projects. Journal of Computing in Civil Engineering, 31(4), (2017)

6. Geng, J. Q., Weng, L. P., \&Liu, S. H.. An improved ant colony optimization algorithm for nonlinear resource-leveling problems. Computers \& Mathematics with Applications, 61(8), (2011)

7. J.Weglarz, On certain models of resource allocation problems, Kybernetics 9 61-66. (1981)

8. Joy, J., Rajeev, S., \&Narayanan, V.. Particle Swarm Optimization for Resource Constrained-project Scheduling Problem with Varying Resource Levels. Procedia Technology, 25, (2016)

9. K.Neumann, J.Zimmermann, Procedures for resource leveling and net present value problems in project scheduling with general temporal and resource constraints, European Journal of Operational Research 17 (2) (2000)

10. Li, H., Zhe, X., \&Demeulemeester, E.. Scheduling Policies for the Stochastic Resource Leveling Problem. Journal of Construction Engineering \& Management, 141(2), (2015)

11. Liu, J., \&Lu, M. (2019). Robust Dual-Level Optimization Framework for Resource-Constrained Multiproject Scheduling for a Prefabrication Facility in Construction. Journal of Computing in Civil Engineering, 33(2), (2019)

12. Menesi, W., \&Hegazy, T.. Multimode ResourceConstrained Scheduling and Leveling for PracticalSize Projects. Journal of Management in Engineering, (2014)

13. Mohammad Ranjbar, Mohammad Khalilzadeh,Fereydoon Kianfar,Kobra Etminani. An optimal procedure for minimizing total weighted resource tardiness penalty costs in the resourceconstrained project scheduling problem [J]. Computers \& amp; Industrial Engineering, 62(1)2011,.

14. Nima Zoraghi, Aria Shahsavar, Babak Abbasi, Vincent Van Peteghm.Muti-mode resourceconstrained project scheduling problem with material ordering under bonus-penalty policies.[J]. TOP, ,25(1). 2017

15. Piryonesi, S. M., Nasseri, M., \&Ramezani, A.. Resource Leveling in Construction Projects with Activity Splitting and Resource Constraints: A Simulated Annealing Optimization. Canadian Journal of Civil Engineering, (2018)

16. Ponz-Tienda, J. L., Yepes, V., Pellicer, E., \&MorenoFlores, J.. The Resource Leveling Problem with multiple resources using an adaptive genetic algorithm. Automation in Construction, 29(Complete), 161-172(2013).

17. Ponz-Tienda, J. L., Salcedo-Bernal, A., Pellicer, E., \&Benlloch-Marco, J.. Improved Adaptive Harmony Search algorithm for the Resource Leveling Problem with minimal lags. Automation in Construction, 77, 82-92 (2017). doi: 10.1016/j.autcon.2017.01.018
18. R.Slowinski, Muti-objective network scheduling with efficient use of renewable and nonrenewable resources,European Journal of Operational Research 7 265-273(1981).

19. Selvam, G., \&Tadepalli, T. C. M.. Genetic algorithm based optimization for resource leveling problem with precedence constrained scheduling. International Journal of Construction Management, (1), 1-10 (2019).

20. S Shadrokh, F.Kianfar, A genetic algorithm for resource investment project scheduling problem,tardiness permitted with penalty, European Journal of Operational Research 181 (1) 86-101. (2007)

21. Wang, H. X., Wang, Z. H., \&Zhu, M.. Differential evolution algorithm for multi-project resource leveling problem. Journal of Interdisciplinary Mathematics, 20(6-7), 1383-1386. (2017)

22. Zhong, Y., Chen, Z., \&Zhou, Z.. Resource Allocation Model and Strategy Research of Large-scale Construction Project: System Dynamics Modeling and Simulation. Chinese Journal of Management Science, 24(3), 125-132. (2016) (in Chinese) 